\title{
Are marginals different? Evidence from British elections 1950-2015
}

\author{
Caladan Barkovic-Parsons ${ }^{1} \cdot$ Robert Hodgson $^{2}$ • \\ John Maloney ${ }^{1}$ (D)
}

Received: 8 December 2015/ Accepted: 27 February 2017/Published online: 21 March 2017

(C) The Author(s) 2017. This article is an open access publication

\begin{abstract}
We analyse the results of British general elections from 1950 to 2015. In our model, voting is both instrumental and expressive, and is driven both by ideology and the perceived valence of different parties. On most assumptions the model predicts that the safer the seat the lower the swing. The exception is where ideological factors are relatively dominant in instrumental voting, and valence factors are relatively dominant in expressive voting. In this case the highest swings might be in the safest seats. Alternatively swing might peak at intermediate majorities, and this is what we find when we look at swings between Conservative and Labour in seats held by one or other of these parties. We also find that marginals behave more distinctively when the national result is expected to be close or when there has been another general election recently; and that at least some voters have a sense of what is a 'bellwether' seat i.e. one that would be marginal in a close election. However in those seats where the main contest has been between the Conservatives and Liberal Democrats, the swing is positively related to the closeness of the contest.
\end{abstract}

Keywords Marginal · British · Election · Swing · Voting

\section{Introduction}

Over the last 60 years there has been a trend-although not a steady or uninterrupted one-for constituencies in British general elections to show less uniform swings. How far these are a matter of 'noise' and how far underpinned by shifting regional and

John Maloney

J.Maloney@ex.ac.uk

1 University of Exeter Business School, Streatham Court, Rennes Drive, Exeter EX4 4PU, England, UK

2 Department of Health Sciences, University of York, Heslington YO10 5DD, England, UK 
socioeconomic electoral patterns has been investigated intensively. In this article we are going to look specifically at differences in the behavior of marginal, fairly safe and very safe seats. The two uncontested propositions about marginal seats in Britain are that there are fewer than there were (at least if you count them in terms of the two-party share of the vote) and that turnout is higher in marginal seats than in safe ones. But does living in a marginal constituency affect the way people vote as opposed to the likelihood that they vote at all? Different types of seat might exhibit different degrees of absolute volatility, or stronger and weaker adherence to the overall national trend in a general election, or a different propensity to swing away from and back to the government of the day. In this article we assemble the evidence from every general election between 1950 and 2015 to try to answer these questions. We also ask whether being marginal or becoming marginal is more likely to produce distinctive voter behaviour, and whether it is right to focus in the first place on seats with current small majorities, as opposed to those which would be close in the event of a close national result - the so-called bellwether seats.

In what follows, we use the terms marginal and safe in a comparative sense. One seat is more marginal (less safe) than another if the winner's percentage margin (as a share of all votes cast) is smaller. By a swing between two parties we refer to the mean of the firstplace party's percentage gain (again as a share of the total vote for all parties) and the second-place party's loss. For much of the time we will be looking at 'swings to gainer'constituency swings in favour of the party that is gaining ground nationally. Any seat that moves against the national trend therefore has a negative swing to gainer.

\section{Literature}

If people vote only when expected benefit (utility from deciding the government times the probability that your vote will do so) exceeds the cost of voting, no rational person will vote. It is always open to political scientists to attribute bad statistical sense to voters, so that they exaggerate their chances of personally ejecting or saving their MP, or even the government itself. But 'minimum rational choice' and 'general incentives' have been the more popular options over the years. According to 'minimum rational choice theory' (Riker and Ordeshook 1973) voters also define their political efficacy 'in terms of the influence of groups of people like themselves. Consequently, they are motivated to take action because they feel they can collectively make a difference' (Clarke et al. 2004, p. 248). If these groups include your political allies within your own constituency, and collective efficacy is related to the likelihood that collective action will be pivotal, we have a rationale for higher voter turnout rates in marginal seats. The general incentives model (Whiteley et al. 1994; Whiteley and Seyd 2002) encompasses the minimum rational choice approach but adds other motives for voting, in particular the expressive motive first put forward by Buchanan (1954). And, in doing so, it provides not just a reason for higher turnout in marginals but a rationale for a different pattern of voting. If voters have a mixture of instrumental and expressive motives, the relative power of the latter will decline as the efficacy of the vote increases (Tullock 1971). Consequently, voters who would like to express a protest against the government, but still prefer it to the main opposition party, might give it a grudging vote in a marginal seat which they would withhold in a safe one.

This, then, is our first reason to expect marginal and safe seats to have different patterns of swing. Price and Sanders (1998) extend the analysis by attributing two alternative objectives to disenchanted government supporters 
(a) punish the government as long as its majority is not reduced

(b) punish the government as long as it doesn't lose office

Either of these factors would reduce anti-government swings in marginal seats. But in that case they must reduce any pro-government swings in marginal seats, too. When the trend is towards the government (i.e., increases its majority), some voters in safe seats, previously protesting against the government, will return to it. So will some in the marginals, but not so many, because fewer deserted it in the first place. Whatever the direction of the national swing, then, its beneficiary will gain fewer votes in marginal seats than in safe ones.

Secondly, a generally positive personal vote for incumbent MPs will give parties particularly favorable swings in their own marginal seats taken as a whole. Unless a party captured no seats at all from its opponents at the previous election, its marginals will include a disproportionate number of candidates standing as the incumbent MP for the first time, and thus enjoying an 'incumbency swing' less prevalent in safe seats. Several of the election studies by Steed and/or Curtice (see below) notice an incumbent government holding rather successfully onto its marginals when it is losing ground in general. A particularly strong and persistent effect in their studies is how well a party generally does when its incumbent MP fights a seat he or she gained from an incumbent opponent at the previous election. This 'double incumbency' effect seems to have been particularly striking in the elections of 2005, 1992, 1987 and 1970. (Steed 1970, p. 205; Curtice and Steed 1988, pp. 333-334, 1992, p. 340; Curtice et al. 2005, p. 248). In the 1970 case, Steed finds that the double incumbency effect fully explains why the outgoing Labour government suffered a less hostile swing in its 100 most marginal seats than across the country as a whole. (In 1979, by contrast, when a Labour government was again defeated, but did less badly in its own marginals, Curtice and Steed 1980 found the double incumbency effect to explain only part of the phenomenon.)

The third reason why marginals are different is that parties campaign harder and spend more in marginal seats. Again the most obvious-and well-documented-effect is on turnout. Turnout in marginal constituencies has exceeded average national turnout in every British election since 1950, but the size of this margin has fluctuated substantially. Denver et al. (2003) trace the widening of the gap up to 1979, and its subsequent narrowing during the Thatcher/Major years, only for it to open up again in 1997 and 2001. Controlling for socioeconomic status (a significant determinant of turnout) alters the story insofar as the downturn after 1979 is now backdated to 1966. The question raised is whether higher turnout in marginals comes from the more intensive campaigning they undoubtedly attract or whether the expected closeness of the result would have called out more voters anyway. Denver, Hands and McAllister conclude that both of these factors matter, though their relative strength appears to vary significantly between one election and another.

In addition, Curtice and Steed (1980) have found that the turnout effect of being a marginal seat rises in elections that follow hard on their predecessors (1951, 1966, October $1974)$ and then drops back at the subsequent election $(1955,1970,1979)$. Presumably this is because recent memories of the previous election include a memory of the constituency's marginal status. If so, this is itself evidence that higher turnout in marginals is not explained solely by more spending and harder campaigning there. So, indirectly, is the finding by Clarke et al. (2004) that turnout is higher across the country when the national result is close, given the lack of any inverse correlation between national winners' margins and combined campaign spending. 
To assert that more people would vote in marginal constituencies even if no party spent a penny on them is not, of course, to say that campaigning is ineffective. Indeed, recent evidence suggests not only that it is more effective than was previously thought, but that the two main parties, even if they spend equal sums of money nationally, do not just neutralize one another's efforts. Some of this is because parties tend to spend more in their own constituencies (Clarke et al. 2004). All of this means that we would expect to see each party performing better in the marginals that it holds than in those it is trying to win over, and Clarke et al. (2004) find exactly this in the 2001 election. In the 2015 election, the difference was particularly striking. Across the 50 most marginal seats, the Conservativeheld ones swung by an average of $1.2 \%$ towards the Conservatives and the Labour ones by $2.5 \%$ towards Labour.

What the above facts imply is that good reasons exist to think that non-uniformity of constituency swings is likely to be systematic as well as random, and a simple relation whereby marginal seats feature smaller or larger swings than safe ones is unlikely. And certainly the successive analyses of election swings by Michael Steed and John Curtice do not add up to any such pattern. Aggregating their surveys, however, is not easy. The definition of a marginal changes between surveys; in 1987, for example, they looked only at government marginals; in elections that follow boundary changes they do not try to identify marginals at all. This is not a criticism. Different approaches are appropriate to different electoral situations. But it does mean that an aggregative study of very safe, moderately safe, marginal and bellwether seats reaching down from 1950 has yet to be conducted. That is what we are going to do.

\section{Model}

In the model that follows, expressive voting (voting to demonstrate support for a party regardless of an election's result) and instrumental voting (voting to try and affect the outcome of the election) both depend on (1) the parties' respective valences and (2) the voter's ideological distance from the parties.

However the ideological and valence motives for voting are related insofar as a voter's ideology drives his or her perception of valence. It is not just that ideological location colors a voter's view of how well a party is handling a particular issue (Sanders et al. 2011) and how competent a party's leader is (Jacoby 2009). Left and Right also rank the importance of the issues differently. Thus, for instance, even if voters were unanimous that one party is better at handling unemployment and the other at keeping inflation down, their differing weighting of the issues themselves would ensure divergent valence scores across the electorate (Palmer et al. 2013).

Sanders et al. (2011) find that spatial (i.e., ideological) variables have little effect on voting until their indirect effect, operating through valence perception, is isolated and added to the story. In what follows, we lump the direct effects and indirect effects together and define them as ideological voting. Valence voting, therefore, means its 'pure' form, i.e., voting stemming from perceptions of valence that are independent of a voter's ideology. For simplicity, we assume that this perception is common to all voters i.e., that different estimates of valence stem entirely from ideological differences.

So let voter $i$ derive the following expressive utilities from voting for $L$ and $R$ (the two largest national parties) respectively: 


$$
U_{i, L}^{E X P}=\alpha v_{L}-\beta\left|\theta_{i}-\theta_{L}\right| \quad U_{i, R}^{E X P}=\alpha v_{R}-\beta\left|\theta_{i}-\theta_{R}\right|
$$

where $v$ is 'pure' valence as defined above, $\theta$ is ideological location and $\beta$ captures the effects of ideology both directly and indirectly through imputed valence.

Now, over and above any expressive utility, let voter $i$ 's welfare gain from having $L$ 's policies, not R's, implemented be

$$
U_{i, L}^{I N S T}-U_{i, R}^{I N S T}=\gamma\left(v_{L}-v_{R}\right)-\delta\left(\left|\theta_{i}-\theta_{L}\right|-\left|\theta_{i}-\theta_{R}\right|\right) .
$$

Hence, $i$ 's instrumental utility from voting for $L$ is:

$$
p(x) U_{i, L}^{I N S T}-U_{i, R}^{I N S T}=p(x)\left[\gamma\left(v_{L}-v_{R}\right)-\delta\left(\left|\theta_{i}-\theta_{L}\right|-\left|\theta_{i}-\theta_{R}\right|\right)\right]
$$

where $p(x)$ is the perceived probability that $i$ 's vote will be decisive if $i$ lives in constituency $x$.

Hence, putting expressive and instrumental utilities together, and writing $v_{L}-v_{R}$ in future as $v, i$ 's total excess utility from $L$ rather than $R$ is:

$$
U_{i}^{\prime}=\alpha \nu-\beta\left(\left|\theta_{i}-\theta_{L}\right|-\left|\theta_{i}-\theta_{R}\right|\right)+p(x)\left[\gamma \nu-\delta\left(\left|\theta_{i}-\theta_{L}\right|-\mid \theta_{i}-\theta_{R}\right)\right]
$$

or, for a voter between $\theta_{L}$ and $\theta_{R}$,

$$
U_{i}^{\prime}=(\alpha+p \gamma) v-2(\beta+p \delta) \theta_{i}+(\beta+p \delta)\left(\theta_{L}+\theta_{R}\right)
$$

We now assume that voters will vote for a third party or abstain if $\left|U_{i}^{\prime}\right|<y_{i}$, where $y_{i}$ is uniformly distributed across the electorate from 0 to a maximum of $\bar{y}$. (Thus a voter for whom $y_{i}=0$ will always vote for $L$ or $R$, while a voter for whom $y_{i}$ is large enough will be loyal to a third party or abstain in all circumstances.)

Voter $i$, then will

vote $\mathrm{L}$ if $U_{i}^{\prime}>y_{i}$,

vote 3 rd party or abstain if $-y_{i}<U_{i}^{\prime}<y_{i}$

vote $\mathrm{R}$ if $U_{i}^{\prime}<-y_{i}$

We assume that voters in each constituency are normally distributed in terms of $\theta$ around the constituency mean (and median) $\mu_{x}$. We calibrate the $\theta$-axis so that $\mu=0$ in the seat where the $L$ and $R$ votes currently are equal.

Now let $\theta(y)$ be the ideological position of voters for whom $U^{\prime}=y$. It follows that $\theta(\bar{y})$ and $\theta(-\bar{y})$ are the ideological points outside of which all voters support $L$ or $R$, so that the swing in constituency $x$ caused by a small change in $v$ will depend on the number of voters in that constituency within the range $[\theta(-\bar{y}), \theta(\bar{y})]$.

Now let $v$ increase by $d v$. Then from (1):

The value of $\theta$ needed for a voter to reach any given $U^{\prime}$ rises by $\frac{\alpha+p \gamma}{2(\beta+p \delta)} d v$.

This is the size of the ideological interval within which voters previously below $U^{\prime}$ will attain it. Now consider voters for whom $U^{\prime}=y$. These voters are at $\theta(y)$; let their number in seat $x$ be $n_{x}(\theta[y])$.

Thus, the number of voters in seat $x$ whose $U^{\prime}$ reaches $y$ as a result of the increase in $v$ is: $n_{x}(\theta[y]) \cdot \frac{\alpha+p(x) \gamma}{2(\beta+p(x) \delta)} d v$. Of these, given $y_{i}$ 's uniform distribution between 0 and $\bar{y}$, the proportion $1 / \bar{y}$ will start voting $L$ in consequence. 
Thus $L$ 's gain among voters who require $U^{\prime}=y$ in order to vote for it is

$$
\frac{1}{\bar{y}} \cdot n_{x}(\theta[y]) \cdot \frac{2(\alpha+p(x) \gamma)}{\beta+p(x) \delta} d v
$$

or, aggregating across all possible values of $y, L$ 's gain in constituency $x$ is

$$
\frac{1}{\bar{y}} \cdot n_{x}[0, \bar{y}] \cdot \frac{\alpha+p(x) \gamma}{2(\beta+p(x) \delta)} d v
$$

where $n[0, \bar{y}]$ is the number of voters between $\theta=0$ and $\theta=\bar{y}$.

By symmetry $R$ 's loss (of voters whose $U_{i}^{\prime}$ now exceeds, their $-y_{i}$ ) is

$$
\frac{1}{\bar{y}} \cdot n_{x}[-\bar{y}, 0] \cdot \frac{\alpha+p(x) \gamma}{2(\beta+p(x) \delta)} d v
$$

Hence, swing $\left(s_{x}\right)=1 / 2\left(L^{\prime}\right.$ s gain $+R^{\prime}$ s loss $)=\frac{1}{\bar{y}} \cdot n_{x}[-\bar{y}, \bar{y}] \cdot \frac{\alpha+p(x) \gamma}{4(\beta+p(x) \delta)} d v$

where the second term gives the number of 'marginal' voters in the constituency and the third term measures the effectiveness of a valence change in shifting them.

Since the median voter in seat $x$ is at ideological position $\mu_{x}$, while the median voter in the most marginal seat is at ideological position 0 , it follows that that greater is the absolute magnitude of $\mu$ the less marginal is the seat. We now consider the sign of $\frac{d s}{d|\mu|}$, i.e., whether swings will increase or decrease as seats become less marginal. Clearly the first term in (3) is independent of $|\mu|$. We now show (1) that the second term is declining in $|\mu|$ and (2) the third term might be either declining or increasing in $|\mu|$.

$$
\text { Since } n[-\bar{y}, \bar{y}]\left|\theta \sim N\left(\mu, \sigma^{2}\right) \equiv n[-\bar{y}-\mu, \bar{y}-\mu]\right| \theta \sim N\left(0, \sigma^{2}\right) \text {, }
$$

$$
\text { therefore, } \frac{d}{d \mu_{x}}\left(n_{x}[-\bar{y}, \bar{y}]\right)=n\left(\bar{y}-\mu_{x}\right)-n\left(-\bar{y}-\mu_{x}\right) \mid \quad \theta_{x} \sim N\left(0, \sigma^{2}\right)
$$

which is negative (positive) when $\mu_{x}>(<) 0$. Thus the further the constituency is from the knife-edge seat, whether to its left or to its right, the lower is this component of the swing. This is just saying that marginal seats have more marginal voters.

2.

$$
\frac{d}{d p}\left(\frac{\alpha+p \gamma}{\beta+p \delta}\right)=\frac{\gamma(\beta+p \delta)-\delta(\alpha+p \gamma)}{(\beta+p \delta)^{2}}=\frac{\beta \gamma-\alpha \delta}{(\beta+p \delta)^{2}}
$$

Thus, $\frac{\alpha+p \gamma}{\beta+p \delta}$ is increasing in $p$ and, hence (assuming $\frac{d p}{d|\mu|}<0$ ) decreasing in $|\mu|$ iff $\beta \gamma>\alpha \delta$.

We now consider some implications. Throughout, we assume that aggregate voting has both an instrumental and an expressive component.

Proposition 1 If $\beta \gamma>\alpha \delta$, then the safer is the seat the smaller is the swing.

Here, both the second and third terms of (3) are decreasing in $|\mu|$.

The logic goes as follows. The component terms of $\beta \gamma>\alpha \delta$ are:

$\alpha=$ responsiveness of expressive voting to valence

$\gamma=$ responsiveness of instrumental voting to valence 
$\beta=$ responsiveness of expressive voting to ideological distance between voter and party

$\delta=$ responsiveness of instrumental voting to ideological distance between voter and party.

But if $\beta \gamma>\alpha \delta$, then $\beta / \delta>\delta / \gamma$. This means that, compared with their respective sensitivities to valence, expressive voting is relatively sensitive to, and instrumental voting relatively insensitive to, ideological differences between the voter and the party. But in a safe seat, the expressive motive is relatively strong and the instrumental one relatively weak. It follows that voting in these seats is ideology- rather than valence-driven, so that it requires a large change in valence to get constituents to switch their votes. In this case, then, a given change in valence will be less effective in safe seats than in marginal ones, and this reinforces their existing tendency towards smaller swings, given by the fact that they have fewer marginal voters in the first place.

Proposition 2 If $\beta \gamma<\alpha \delta$, then no monotonic relation may exist between marginality and swing.

In this case, the second term of (3) is decreasing, but the third term increasing in $|\mu|$.

Why? This time the intuition is as follows. When $\alpha \delta>\beta \gamma$ (i.e., $\alpha / \gamma>\beta / \delta$ ) it is instrumental voting that is relatively sensitive to, and expressive voting relatively insensitive to, ideological differences between the voter and the party. It is thus in the marginal seats (where instrumental voting is most important) where the vote is driven most strongly by ideology, and where it thus requires the largest change in valence to get voters to switch. In this case a given change in valence is more effective in safe seats than in marginal ones, and this effect counteracts the latter's tendency towards smaller swings, given by the fact that there are fewer voters on the margin in the first place. With these two effects now working in opposite directions, a monotonic relation between existing majority and swing may no longer exist.

All of the foregoing considerations cast a new light on the proposition that a government falling out of favor may lose more support in safe seats (where voters feel free to express their feelings of protest) than in marginal ones (where some voters would like to protest but do not actually want the government to be ejected from office.) The implicit assumption behind this story is some voters are expressively anti-government but instrumentally pro-government. This could be the case-indeed it corresponds to the case where $\alpha \delta>\beta \gamma$ in our model (as the government's valence declines, expressive sentiments change faster than instrumental calculations). But it doesn't have to be the case-it is equally possible that the declining valence has more impact on the instrumental motive than on the expressive one. In that case relatively few voters will be deserting the government as a protest, and many more doing so as a strategy. As the marginal seats are the ones where strategy is most preferred to protest, the government will do worst in the seats where it can least afford to lose ground.

But so far we have been assuming that national swings are caused by changes in the valences of the parties. What if voters are switching because one of the parties has shifted its ideological position?

Proposition 3 If one or both parties shift their ideological position, then the safer the seat the smaller the swing.

Suppose that $\theta_{R}$ rises by $d \theta$. Then from (1) the value of $\theta$ needed for a voter to reach any given $U^{\prime}$ rises by $d \theta / 2$. Hence, $d \theta / 2$ replaces $\frac{\alpha+p \gamma}{2(\beta+p \delta)} d v$ in (2), so that (3) becomes $s_{x}=\frac{1}{\bar{y}} \cdot n_{x}[-\bar{y}, \bar{y}] d \theta / 4$. Since, as we have seen, $n_{x}[-\bar{y}, \bar{y}]$ is declining in $|\mu|$ we have a monotonic inverse relation between existing majority and swing. Clearly, the same relation 
would also hold if both parties shifted ideology, or (which comes to the same thing) the electorate itself underwent a wholesale ideological move one way or the other.

To summarise then: (1) If swings are driven by valence changes, and valence is more dominant in instrumental voting than in expressive voting, the largest swings will be in the most marginal seats. (2) If swings are driven by valence changes, and valence is more dominant in expressive voting than in instrumental voting, then the ideological position of the swing voter shifts furthest in safe seats, compensating for the fact that they have fewer swing voters to start with, and possibly producing either an increasing or a hump-shaped relation between existing majority and swing. [It cannot be U-shaped because at $\mu=0$, swing is increasing in $\mu$ on account of the second term in Eq. (3) being independent of itsee Eq. (4)]. (3) If parties are gaining or losing ground because their own ideology, or that of the electorate, has shifted, again the swing will be larger the more marginal the seat. Therefore, should we find either an increasing or a hump-shaped relation between existing majority and swing, the evidence is consistent with (2) only.

Before leaving the model, note that the parameters $\alpha, \beta, \gamma$ and $\delta$ together ensure that the relation between $p$ and swing can vary by several orders of magnitude. Inspection of Eq. (5) will show that a large (small) difference between the products $\alpha \delta$ and $\beta \gamma$ will mean that small (large) differences in $p$ between different constituencies can produce large (small) differences in swing. This is important, given the finding in the British Election Study (2005) that the marginality of the seat in which a voter lives makes only a very small difference in the perceived probability that they can affect the result. ${ }^{1}$ As will be seen in the results section of this article, the difference in average swing between marginal and safe seats, though not great, is greater than one might at first sight expect given the British Election Study's results. This points to a large difference in the respective magnitudes of $\alpha \delta$ and $\beta \gamma$.

\section{Method and data}

To analyze the impact of a seat's marginality on swing we make use of all constituency results (Northern Ireland excepted) wherein either Labour or the Conservatives won between 1950 and 2015. However, the elections of February 1974, 1983, 1997 and 2010, all of which followed major boundary changes, are used only to calculate swings at the succeeding election (and to establish which seats being contested by incumbent MPs). Our basic regression model is run using OLS and is as follows:

$$
\text { Swing }_{j t}=\beta_{1} \mathbf{M}_{\mathbf{j t}}+\beta_{2} \mathbf{X}_{\mathbf{j t}}+\beta_{3} \mathbf{D}_{\mathbf{t}}
$$

here $j$ refers to the constituency and $t$ to the general election. Swing is swing between Labour and Conservative, ${ }^{2}$ with positive swing representing swing to the gainer (party favored by the national swing). $\mathbf{M}$ is a matrix of variables measuring the marginality of the seat, $\mathbf{X}$ is a matrix of conditioning variables, and $\mathbf{D}$ is a set of year dummies, i.e. fixed effects for each election. Fixed effects for each constituency would not be appropriate

\footnotetext{
1 This is the nearest that existing surveys get to asking voters directly if they would have voted differently had their constituency been more or less marginal. But see, e.g., Blais and Rheault (2011), who find that moving from the least to the most marginal constituency in Canada raises the proportion of the most 'politically attentive' voters who think that their votes could be pivotal by 52 percentage points.

2 This includes swings between Conservative and Labour in seats where one of these parties won, but the other was not the runner-up. We declined to exclude such seats; they are not the only ones in which swings may have been distorted by tactical voting, and in any case a control variable in the form of 'other parties' vote' is entered.
} 
because the majority of constituencies consistently were safe or marginal between each set of boundary changes. Controlling for constituency characteristics would thus largely control for just the variable we need to isolate for analysis.

For the purposes of this article we use traditional or 'Butler' swing. Traditional or 'Butler' swing looks at parties' shares of the entire vote and averages one party's gain and another one's loss. Two-party swing replaces shares of the poll by shares of the combined vote of the two parties concerned. In some contexts, two-party swing captures the dynamics of the political process better than traditional swing (For example, it does not find a spurious 'swing' between the two main parties as a result of voters switching between third parties and abstention). Nonetheless, we use the traditional version of swing in this article. That is because much of our analysis is to do with the possible behavioral effects of voters' realization that they are, or are not, in a marginal constituency. Public discussion of the swing needed to topple an MP or a government is couched entirely in the language of traditional swing. 'The Tories' 96th most winnable seat' is not the one where the Conservative-Labour vote ratio is the 96th nearest to $50 \%$ but the one where Labour's percentage margin over the Conservatives, as a proportion of the entire vote, is the 96th smallest. Commentators on election night do not present two-party swings, nor do they appear to have them in mind when they say 'that's one Labour should have won if it's seriously hoping to form a government'. Consequently, we use Butler swing as the one most likely to shape electors' perceptions of the consequences of their vote.

A further important methodological point is how to model the kind of incumbency effects, postulated and confirmed by Steed and Curtice, whereby a sitting incumbent might specifically brake or accelerate the national electoral trend. What we do is create two dummy variables, INCUMBENT and LAG.INCUMBENT. INCUMBENT is entered as 1 $(-1)$ if an incumbent MP standing at the current election belongs to the party that is gaining (losing) ground nationally. LAG.INCUMBENT is entered as $1(-1)$ if an incumbent MP standing at the previous election belonged to the party that is gaining (losing) ground at the current election. Thus, if, for example, the same MP fought both elections we would expect the coefficients on INCUMBENT and LAG.INCUMBENT to sum to zero (no incumbency swing will be observed at this election because the MP already will have been enjoying an incumbency advantage). If incumbents of opposing parties respectively fought the two elections, we would expect a double incumbency effect, such that the product of INCUMBENT and its coefficient, and that of LAG.INCUMBENT and its coefficient, would have the same signs. ${ }^{3}$

\section{Results}

Column (1) of Table 1 regresses constituency swing to national gainer on percentage majority, other parties' (i.e., not Labour or Conservative) shares of the vote and incumbency score as just defined ( $p$-values in brackets). The coefficient on majority is insignificant, thus giving no reason to believe that marginal seats in general reflect the

\footnotetext{
3 Suppose, for instance, that a Labour MP had been defeated in 2001 and his or her Conservative successor stood as the incumbent in 2005. As the national swing in 2005 was to the Conservatives, the seat would have a LAG.INCUMBENT dummy of -1 . A defeat of the previous Labour incumbent ought to magnify any swing to the Conservatives in 2005, so we would expect the lagged dummy and its coefficient to have a positive product, i.e., the coefficient is predicted to be negative. The INCUMBENT dummy is 1 (national gainer is the same party is the current incumbent) and we would again expect this dummy and its coefficient to have a positive product. Therefore, the coefficient on INCUMBENT should be positive.
} 
Table 1 Relation of swing to majority

\begin{tabular}{|c|c|c|c|}
\hline (1) & $\begin{array}{l}\text { Swing to gainer } \\
\text { (2) }\end{array}$ & $\begin{array}{l}\text { Swing to gainer } \\
\text { (3) }\end{array}$ & Swing to gainer \\
\hline Majority & $\begin{array}{l}-0.0012 \\
(0.660)\end{array}$ & $\begin{array}{l}0.0678 * * * \\
(0.000)\end{array}$ & - \\
\hline Majority squared & - & $\begin{array}{l}-0.0013 * * * \\
(0.000)\end{array}$ & - \\
\hline Conservative majority & & & $\begin{array}{l}0.1833 * * * \\
(0.000)\end{array}$ \\
\hline Cons. maj. squared & - & - & $\begin{array}{l}-0.0049 * * * \\
(0.000)\end{array}$ \\
\hline Labour majority & & & $\begin{array}{l}0.0472 * * * \\
(0.000)\end{array}$ \\
\hline Lab. maj. squared & - & - & $\begin{array}{l}-0.0007 \\
0(0.000)\end{array}$ \\
\hline Labour seat & - & - & $\begin{array}{l}0.5829 * * * \\
(0.001)\end{array}$ \\
\hline Other parties & $\begin{array}{l}-0.011^{*} \\
(0.074)\end{array}$ & $\begin{array}{l}0.0064 * * * \\
(0.001)\end{array}$ & $\begin{array}{l}-0.0199 * * * \\
(0.003)\end{array}$ \\
\hline Incumbent & $\begin{array}{l}0.8018 * * * \\
(0.000)\end{array}$ & $\begin{array}{l}0.8190 * * * \\
(0.000)\end{array}$ & $\begin{array}{l}0.8362 * * * \\
(0.000)\end{array}$ \\
\hline Lag incumbent & $\begin{array}{l}-0.8269 * * * \\
(0.000)\end{array}$ & $\begin{array}{l}-0.8434 * * * \\
(0.000)\end{array}$ & $\begin{array}{l}-0.8216^{* * *} \\
(0.000)\end{array}$ \\
\hline 1951 & 1.134 & 0.601 & 0.112 \\
\hline 1955 & 1.555 & 1.014 & 0.551 \\
\hline 1959 & 1.046 & 0.519 & 0.091 \\
\hline 1964 & 3.909 & 3.415 & 2.942 \\
\hline 1966 & 3.056 & 2.555 & 1.959 \\
\hline 1970 & 4.741 & 4.277 & 3.668 \\
\hline 1974 (Oct) & 2.190 & 1.755 & 1.141 \\
\hline 1979 & 4.833 & 4.388 & 3.767 \\
\hline 1987 & 2.872 & 2.429 & 1.857 \\
\hline 1992 & 3.430 & 2.949 & 2.467 \\
\hline 2001 & 2.124 & 1.746 & 1.093 \\
\hline 2005 & 3.762 & 3.303 & 2.736 \\
\hline 2015 & 1.402 & 1.012 & 0.503 \\
\hline Adjusted $\mathrm{R}^{2}$ & 0.495 & 0.503 & 0.520 \\
\hline No. of obs. & 6231 & 6231 & 6231 \\
\hline
\end{tabular}

Constituency results between 1950 and 1997 are from Caramani, D., Elections in western Europe since 1815: electoral results by constituencies (London: Macmillan, 2000). Constituency results for 2001 and 2005 are taken from Norris P., The British Parliamentary Constituency Database, 1992-2005 (Release 1.3) Constituency results for 2010 and 2015 are taken from the British Election Studies for those elections (http:// www.britishelectionstudy.com) The incumbency status of candidates is compiled from Whitaker's Almanack

* significant at $10 \%$ level, *** significant at $1 \%$ level 
national trend at an election any more or less strongly than safe ones. It is possible, though, that we are imposing a linear trend on a non-linear relationship. Consequently, column (2) tries out a quadratic version, with swing to gainer regressed on both percentage majority and its square. Both coefficients are now significant at the $1 \%$ level; their respective positive and negative signs give us a humped curve. The downturn of the hump, however, comes quite late: it takes a majority of $25.6 \%$ before the swing starts to turn down again. The implication, then, is that the safer the seat, the more strongly it follows the national trend, except for a slight reversal of the picture when seats are very safe.

Before trying to interpret this result, we make a distinction between Labour and Conservative-held seats. According to column (2), both the linear and the quadratic relationship between majority and swing are stronger when the seat is Conservative, but the ratio of the linear to the quadratic coefficient is smaller, implying that Conservative seats reach their 'hump' at a much smaller majority than do Labour ones. Figure 1 illustrates.

But the fact, so strikingly shown here, that swings are more variable in Conservativeheld seats than in Labour ones does not mean that Conservative seats simply have larger swings. The two lines compare swings in a party's seats with the swing in that party's most marginal seat. But, as the coefficient on LABOUR SEAT in column 3 of Table 1 shows, the most marginal Labour seats exhibit larger swings, on average, than the most marginal Conservative ones. When we allow for that, by plotting all swings in relation to that in the most marginal Conservative seat, the picture is rather different. Conservative-held seats continue to have more variable swings, but not necessarily larger ones. More research is needed on the causes of this (Fig. 2).

We said earlier that the difference in swings between marginal and safe seats, though fairly modest even in the Conservative case, is still large in relation to the differences in voters' estimates of $p$. This, we saw, indicates that $\alpha \delta$ and $\beta \gamma$ are of unequal strength. We can now go further. Our results indicate that $\alpha \delta$ exceeds $\beta \gamma$. If, furthermore, we accept the finding of some recent scholars that the valence motive for voting greatly outweighs the 'spatial', i.e., ideological one, then $\alpha$ is the strongest of the parameters, i.e., voting that is expressive and valence-driven dominates the other three varieties.

Another thing to notice from these results is the virtual equivalence of the coefficients on INCUMBENT and LAG.INCUMBENT. A party, it seems, can feel indifferent between losing a hostile incumbent and gaining a friendly one. And note, finally, that parties' campaigning efforts - with the well-established consequence that they are better at holding their own marginals than winning those of the other side-cannot explain why swings become larger as seats become safer. A party putting its best efforts into its marginals will indeed suffer a less hostile swing there when it is losing ground, but will also enjoy a larger swing there when it is gaining. And in any case, it is becoming a marginal, not being a marginal, that apparently leads to more strenuous campaigning than before and might therefore alter the swing. However, when we regressed swings on the first differences of $M A J$ and $M A J^{2}$, we found no significant relation.

\section{Some extensions}

We now consider some factors that might affect voters' perceptions of their ability to affect the result. So far as these change $p(x)$, they will alter the relative weights of expressive and instrumental voting and, hence, the relation between existing majority and swing. In the first place, voting may become more expressive and less instrumental when little doubt 




Fig. 1 Difference in swing between Labour and Conservative-held seats

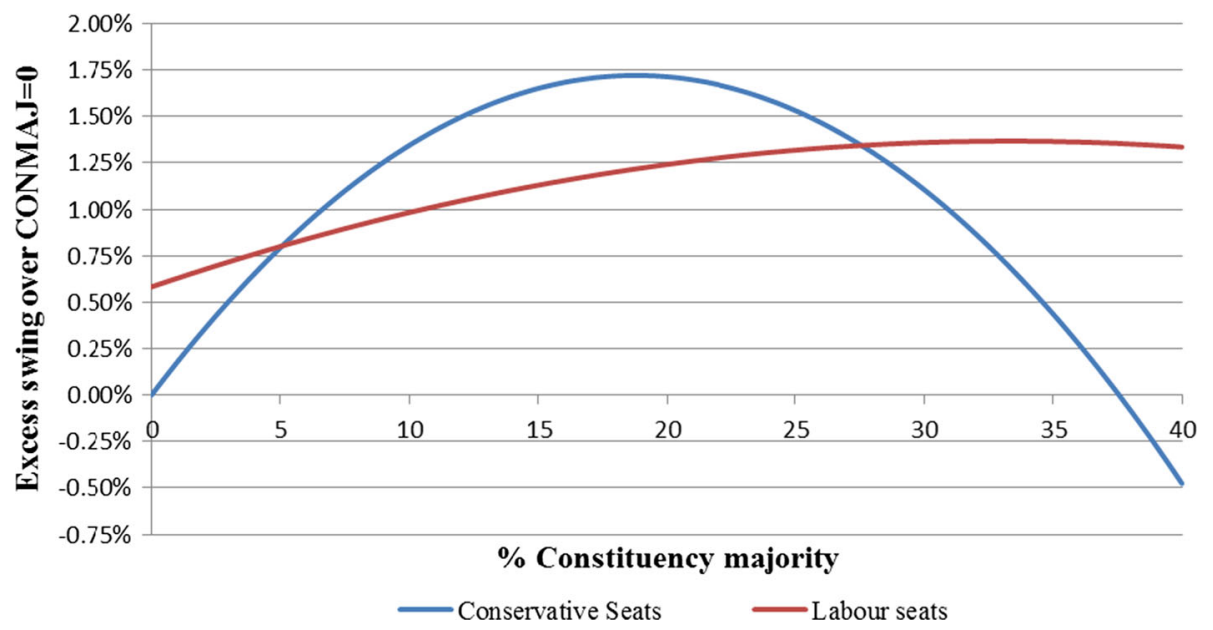

Fig. 2 Swings in Conservative seats are more sensitive to existing constituency majority

exists about who is going to win nationally. Swinging the result in a marginal seat may seem less important to the voter when the marginal seat has no apparent chance of swinging the national outcome. The difference in swing between marginal and safe seats would then be less pronounced. Thus, we create the interactive variables MAJ $* N A T L E A D$ and $M A J^{2} * N A T L E A D$, where NATLEAD is the national percentage lead (over the runnerup) of the election winner. Should the coefficient on MAJ $* N A T L E A D$ be significant and opposite in sign to that on $M A J$, that would be consistent with our conjecture - that the more decisive the national result, the less distinctive the voters' behavior in marginal seats.

Column (1) of Table 2 shows some evidence for the conjecture. MAJ * NATLEAD and $M A J^{2} * N A T L E A D$ are both statistically significant and opposite in sign to $M A J$ and $M A J^{2}$. It seems that marginal seats do behave more like safe ones when only the constituency result is at stake. The above does assume, however, that voters' expectations are best 
Table 2 Are marginals less different when the national result isn't marginal? Sources: Constituency results and incumbency scores as in Table 1. Opinion poll figures from Butler and Butler $(2000,2006)$ and www. bbc.co.uk/news, accessed May 2015

\begin{tabular}{|c|c|c|c|}
\hline & Swing to gainer & Swing to gainer & Swing to gainer \\
\hline MAJ & $\begin{array}{l}0.1092 * * * \\
(0.000)\end{array}$ & $\begin{array}{l}0.0887 \text { *** } \\
(0.000)\end{array}$ & $\begin{array}{l}0.1451^{* * * *} \\
(0.000)\end{array}$ \\
\hline $\mathrm{MAJ}^{2}$ & $\begin{array}{l}-0.0025^{* * *} \\
(0.000)\end{array}$ & $\begin{array}{l}-0.0020 * * * \\
(0.000)\end{array}$ & $\begin{array}{l}-0.0032 \\
(0.000) * * *\end{array}$ \\
\hline MAJ * NATLEAD & $\begin{array}{l}-0.0082^{* * *} \\
(0.009)\end{array}$ & - & - \\
\hline $\mathrm{MAJ}^{2} *$ NATLEAD & $\begin{array}{l}0.0002 * * * \\
(0.000)\end{array}$ & - & - \\
\hline MAJ * POLLLEAD & - & $\begin{array}{l}-0.0037^{*} \\
(0.076)\end{array}$ & - \\
\hline $\mathrm{MAJ}^{2} *$ POLLLEAD & - & $\begin{array}{l}0.0001 * * * \\
(0.001)\end{array}$ & - \\
\hline Other parties & $\begin{array}{l}-0.0201 * * * \\
(0.002)\end{array}$ & $\begin{array}{l}-0.0196^{* * *} \\
(0.002)\end{array}$ & $\begin{array}{l}-0.0349 * * * \\
(0.007)\end{array}$ \\
\hline Incumbent & $\begin{array}{l}0.8091 \text { *** } \\
(0.000)\end{array}$ & $\begin{array}{l}0.7991 * * * \\
(0.000)\end{array}$ & $\begin{array}{l}0.4506^{* * * *} \\
(0.010)\end{array}$ \\
\hline Lag incumbent & $\begin{array}{l}-0.8311^{* * * *} \\
(0.000)\end{array}$ & $\begin{array}{l}-0.8204 * * * \\
(0.000)\end{array}$ & $\begin{array}{l}-0.3719 * * * \\
(0.007)\end{array}$ \\
\hline 1951 & 0.591 & 0.605 & 0.307 \\
\hline 1955 & 0.978 & 1.024 & - \\
\hline 1959 & 0.532 & 0.522 & - \\
\hline 1964 & 3.289 & 3.405 & - \\
\hline 1966 & 2.613 & 2.555 & 2.334 \\
\hline 1970 & 4.244 & 4.278 & - \\
\hline 1974 (Oct) & 1.691 & 1.764 & 1.545 \\
\hline 1979 & 4.434 & 4.376 & - \\
\hline 1987 & 2.711 & 2.444 & - \\
\hline 1992 & 3.019 & 2.939 & - \\
\hline 2001 & 1.77 & 1.607 & - \\
\hline 2005 & 3.203 & 3.284 & - \\
\hline 2015 & 1.067 & 0.918 & - \\
\hline Adj $R^{2}$ & 0.503 & 0.503 & 0.429 \\
\hline No. of obs. & 6231 & 6231 & 1611 \\
\hline
\end{tabular}

* significant at $10 \%$ level, $* * *$ significant at $1 \%$ level

proxied by the actual result. An alternative measure would be the average of opinion poll forecasts on Election Day. The variable POLLLEAD is the average percentage lead, on polling day and across all polls, of the party forecast to win. As column (2) shows, some support for the conjecture still is found, but the coefficients and significance levels of both interactive variables are down. It would seem that voters' behavior is to an extent driven by their expectation of the national result, and that they are better at predicting this than the 
pollsters-which will surprise no one after the latter's performance at the 2015 general election and 2016 EU referendum.

Because NATLEAD is more significant, we use it in the construction of Fig. 3. The lower position of the curve as NATLEAD increases shows how constituency swings become more uniform as the national result becomes more decisive, as conjectured above. The bunching of the curves as $M A J$ increases indicates the converse: that the national result matters less as seats become safer. Again, we might expect this: as the seat gets safer, voters will care less about the national picture as their hopes of influencing it fade.

The other notable thing about Fig. 3 is that at NATLEAD $=15$, the shape of the curve reverses and it becomes a $U$. Given that the largest lead in our series of elections was 11.4\% (Conservative over Labour) in 1987-leads were larger (though still below 15\%) in 1983 and 1997 but these elections followed constituency boundary changes and were thus used by us only to derive swings at the following elections- the curve is hypothetical and should be treated with caution. All the same, Eq. (3) yields at any rate a partial rationale for its shape.

$$
\text { Swing }\left(s_{x}\right)=1 / 2\left(L^{\prime} \text { s gain }+R^{\prime} \text { s loss }\right)=\frac{1}{\bar{y}} \cdot n_{x}[-\bar{y}, \bar{y}] \cdot \frac{\alpha+p(x) \gamma}{4(\beta+p(x) \delta)} d v
$$

In (3), the only factor preventing a monotonically downward sloping curve was the change in the third term brought about by changes in $M A J$ by way of changes in $p$. But, as argued already, $p$ likely is less sensitive to MAJ when NATLEAD is large. Hence, a downward-sloping curve is more likely when the national result is very lop-sided. Why the curve for $N A T L E A D=15$ should turn up again when $M A J$ is very large remains a puzzle, but we are dealing here with both a small number of very safe seats and a notional overall result way beyond anything actually experienced since 1950 .

Another possibility is that voters' awareness that the seat is marginal and, hence, the way some of them vote, depends on how long ago the last election was. As we have already

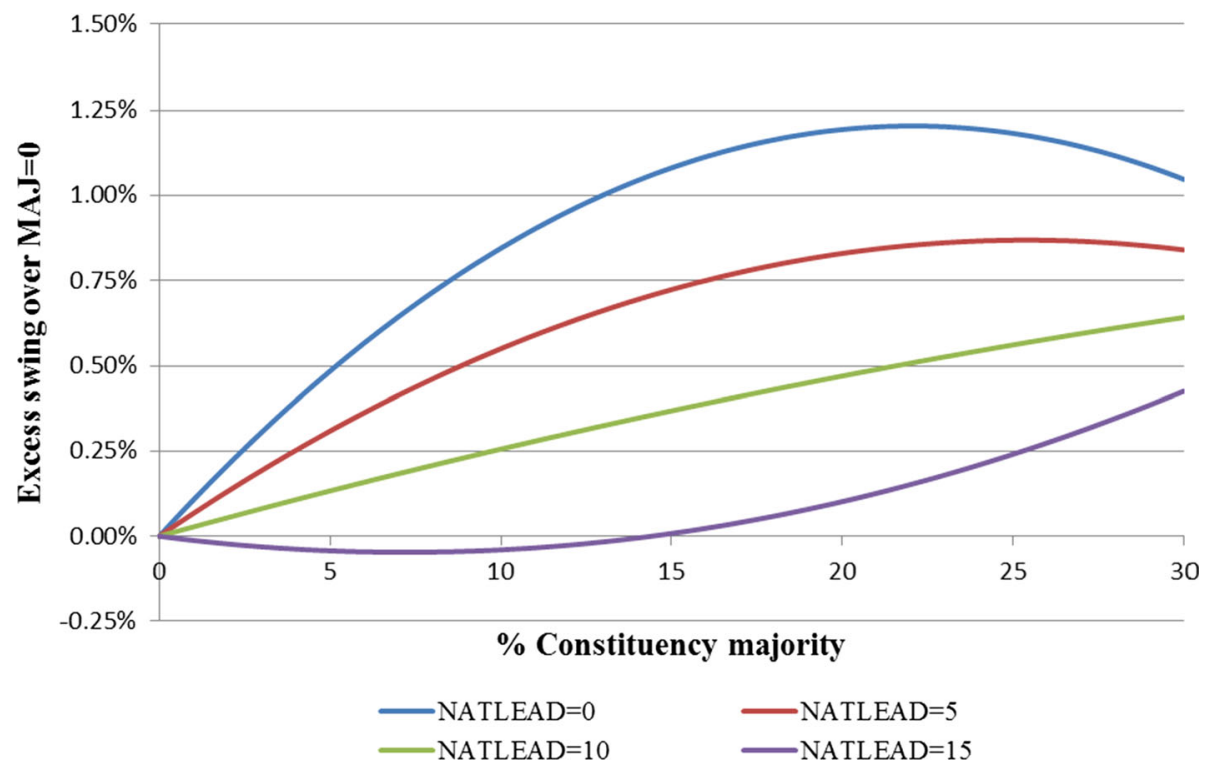

Fig. 3 Marginal seats look more like look more like safe ones when the national result is decisive 
seen, Curtice and Steed have found that turnout in marginals is greater than in nonmarginals and that turnout in marginals is greater still in elections that come quickly after their predecessors $(1951,1966$, October 1974). But is there a parallel effect on the way the inhabitants of marginals vote, as opposed to the likelihood that they vote at all? When we run swing to gainer on majority and majority squared for the elections of 1951, 1966 and October 1974 only, the coefficients on both variables go up (column 3). Three elections comprise a rather meagre data set, but our finding, so far as it goes, implies that voters in marginal seats do behave more distinctively when a recent election reminds them the seat is marginal. ${ }^{4}$

A fundamental objection to the proposition that 'marginals should be different' is that it is not the existing marginals that are going to swing the election, but rather those seats that would be marginal in the event of a close national result (the 'bellwether' seats). The foregoing argument assumes that voters will regard as crucial those seats currently having small majorities. What if they realize that the seats crucial to the outcome are the bellwether seats? If Labour needs to gain 100 seats to win the election, then, even with the certainty of non-uniform swing, the 100th most marginal Conservative seat is far more likely to be decisive than the most marginal one. Might it therefore be in the bellwether seats that we see the most distinctive voting behaviour?

To test this possibility, we re-run column 2 of Table 1 , except that our main independent variable no longer is the existing majority in each seat, but the absolute difference between its percentage government majority (positive or negative) and the percentage government majority in the government's $n$th most marginal seat, where $2 n$ is its parliamentary majority over the main opposition party-i.e., the bellwether seat.

In column 1 , the coefficients on BELL and $\mathrm{BELL}^{2}(0.0757$ and -0.0016) are little different from what they were on MAJ and $\mathrm{MAJ}^{2}(0.0709$ and -0.0013). But when a horse race is run between the two measures in column 2, bellwether wins decisively. Not only do the coefficients on MAJ and $\mathrm{MAJ}^{2}$ shrink by an order of magnitude, they also lose most of their statistical significance (Table 3 ). If voters are better at predicting elections than are opinion polls and have the ability to distinguish between marginal and a bellwether seat, this article is giving them rather a good post-election report.

\section{In the Liberals}

Finally, we compare Conservative-Labour marginals with the second most common form of marginals, those contested between Conservatives and Liberals, where Liberal means Liberal up to 1979, Liberal or SDP in 1983, the Liberal-SDP Alliance in 1987 and Liberal Democrat from 1992 onwards. (Over the period as a whole too few Labour-Liberal marginals exist for analysis to be possible, though they became much more common in and after 2005.) We can skip all the extensions of the last section: we can't analyze nationally close versus decisive Conservative-Liberal results because there weren't any close ones, nor were there enough close Conservative-Liberal contests in the three elections with a recent predecessor for us to ask if these elections were distinctive. And clearly the idea of

\footnotetext{
4 The other notable feature here is that the coefficients on 'incumbent' and 'lag incumbent' have roughly been halved. The weakened results here could reflect new incumbents not having enough time to make themselves well known in the constituency. And the shorter the time is between the two elections, the more likely it is that a defeated MP will stay on and try to win the seat back, and the less likely it is that he or she will have been forgotten in the meantime, in which case the aura of incumbency might be shared between the old and the new member.
} 
Table 3 Do marginals or Bellwethers matter? Sources: as in Table 1
** significant at $5 \%$ level, *** significant at $1 \%$ level

\begin{tabular}{|c|c|c|}
\hline & Swing to gainer & Swing to gainer \\
\hline \multirow[t]{2}{*}{ BELL } & $0.072 * * *$ & $0.049 * * *$ \\
\hline & $(0.000)$ & $(0.000)$ \\
\hline \multirow[t]{2}{*}{ BELL $^{2}$} & $-0.002 * * *$ & $-0.002 * * *$ \\
\hline & $(0.000)$ & $(0.000)$ \\
\hline \multirow[t]{2}{*}{ MAJ } & & $0.029 * *$ \\
\hline & & $(0.014)$ \\
\hline \multirow[t]{2}{*}{$\mathrm{MAJ}^{2}$} & & 0.0001 \\
\hline & & $(0.770)$ \\
\hline \multirow[t]{2}{*}{ Other parties } & $-0.022 * * *$ & $-0.022 * * *$ \\
\hline & $(0.001)$ & $(0.000)$ \\
\hline \multirow[t]{2}{*}{ Incumbent } & $0.780 * * *$ & $0.860 * * *$ \\
\hline & $(0.000)$ & $(0.000)$ \\
\hline \multirow[t]{2}{*}{ Lag incumbent } & $-0.833 * * *$ & $-0.789 * * *$ \\
\hline & $(0.000)$ & $(0.000)$ \\
\hline 1951 & 0.638 & 0.558 \\
\hline 1955 & 1.069 & 0.979 \\
\hline 1959 & 0.582 & 0.493 \\
\hline 1964 & 3.501 & 3.427 \\
\hline 1966 & 2.602 & 2.516 \\
\hline 1970 & 4.256 & 4.164 \\
\hline 1974 (Oct) & 1.796 & 1.721 \\
\hline 1979 & 4.402 & 4.322 \\
\hline 1987 & 2.549 & 2.595 \\
\hline 1992 & 3.107 & 3.061 \\
\hline 2001 & 1.685 & 1.495 \\
\hline 2005 & 3.421 & 3.305 \\
\hline 2015 & 1.044 & 0.982 \\
\hline Adjusted $\mathrm{R}^{2}$ & 0.506 & 0.508 \\
\hline No. of obs. & 6231 & 6231 \\
\hline
\end{tabular}

bellwether seats makes no sense if no one thought the Liberals were liable to win any of the elections.

What we therefore do is take those seats where Conservative and Liberal were in first and second place, in whatever order, and ask if there is a relation between size of majority and swing to national gainer (as between Conservative and Liberal). As can be seen from columns (2) and (4) of Table 4, looking for quadratic functions produces no significant results. But when we look for a linear relation between majority and swing, we find a negative one, provided that we distinguish between Liberal- and Conservative-held seats (col. 3). When we regress swing simply on absolute majority, the significance disappears and the coefficient changes sign (column 1).

So how can marginal seats exhibit the largest swings in Liberal seats and in Conservative seats, but not in seats taken as a whole? The clue lies in the large positive coefficient on 'Liberal seat' in column 3. Liberal-held seats, on average, feature larger swings. But over the period as a whole, Liberals have held relatively, as well as absolutely, fewer 
Table 4 Conservative-liberal majorities and swings. Sources: as in Table 1

\begin{tabular}{|c|c|c|c|c|}
\hline & $\begin{array}{l}\text { Swing to gainer } \\
\text { (1) }\end{array}$ & $\begin{array}{l}\text { Swing to gainer } \\
\text { (2) }\end{array}$ & $\begin{array}{l}\text { Swing to gainer } \\
\text { (3) }\end{array}$ & $\begin{array}{l}\text { Swing to gainer } \\
\text { (4) }\end{array}$ \\
\hline Majority & $\begin{array}{l}0.0157 \\
(0.284)\end{array}$ & $\begin{array}{l}-0.0322 \\
(0.444)\end{array}$ & - & - \\
\hline Majority squared & - & $\begin{array}{l}-0.0009 \\
(0.421)\end{array}$ & - & - \\
\hline Conservative majority & - & - & $\begin{array}{l}-0.6332 * * * \\
(0.003)\end{array}$ & $\begin{array}{l}-0.1367 \\
(0.787)\end{array}$ \\
\hline Cons. maj. squared & - & - & $\begin{array}{l}- \\
-\end{array}$ & $\begin{array}{l}0.0010 \\
(0.364)\end{array}$ \\
\hline Liberal majority & - & - & $\begin{array}{l}-0.0923^{* *} \\
(0.014)\end{array}$ & $\begin{array}{l}-0.0907 \\
(0.268)\end{array}$ \\
\hline Lib. maj. squared & - & - & & $\begin{array}{l}-0.0005 \\
(0.818)\end{array}$ \\
\hline Liberal seat & - & - & $\begin{array}{l}1.755^{* * * *} \\
(0.006)\end{array}$ & $\begin{array}{l}0.4010 \\
(0.629)\end{array}$ \\
\hline Other parties & $\begin{array}{l}-0.0095 \\
(0.707)\end{array}$ & $\begin{array}{l}-0.0015 \\
(0.954)\end{array}$ & $\begin{array}{l}-0.1933 * * * \\
(0.000)\end{array}$ & $\begin{array}{l}-0.0036 \\
(0.891)\end{array}$ \\
\hline Incumbent & $\begin{array}{l}0.9817 \text { *** } \\
(0.000)\end{array}$ & $\begin{array}{l}0.9317^{* * * *} \\
(0.000)\end{array}$ & $\begin{array}{l}0.8521 \text { *** } \\
(0.000)\end{array}$ & $\begin{array}{l}0.9407 * * * \\
(0.000)\end{array}$ \\
\hline Lag incumbent & $\begin{array}{l}-0.980 * * * \\
(0.000)\end{array}$ & $\begin{array}{l}-0.961^{* * *} \\
(0.000)\end{array}$ & $\begin{array}{l}-0.8656^{\text {**** }} \\
(0.000)\end{array}$ & $\begin{array}{l}-0.9583^{* * *} \\
(0.000)\end{array}$ \\
\hline 1951 & -0.3922 & -0.813 & 6.268 & -0.896 \\
\hline 1955 & -7.477 & -7.084 & 1.131 & -7.176 \\
\hline 1959 & 4.856 & 4.795 & 12.816 & 4.727 \\
\hline 1964 & 9.852 & 9.698 & 18.101 & 9.596 \\
\hline 1966 & -0.444 & 0.048 & 7.097 & -0.117 \\
\hline 1970 & 4.075 & 4.343 & 10.656 & 4.220 \\
\hline 1974 (Oct) & -0.359 & -0.215 & 6.672 & -0.330 \\
\hline 1979 & 5.539 & 5.762 & 12.221 & 5.619 \\
\hline 1987 & -0.204 & -0.066 & 7.476 & -0.220 \\
\hline 1992 & -0.100 & -0.009 & 7.678 & -0.162 \\
\hline 2001 & 0.274 & 0.547 & 8.383 & 0.492 \\
\hline 2005 & -0.205 & 0.076 & 7.790 & 0.004 \\
\hline 2015 & 10.351 & 10.615 & 18.065 & 10.4623 \\
\hline Adjusted $\mathrm{R}^{2}$ & 0.467 & 0.482 & 0.506 & 0.471 \\
\hline No. of obs. & 965 & 965 & 965 & 965 \\
\hline
\end{tabular}

** significant at $5 \%$ level, $* * *$ significant at $1 \%$ level

marginal seats, i.e., the preponderance of Conservative over Liberal seats has been even greater in marginal seats than in safe ones. Consequently, when everything is lumped together, safe seats have larger swings because safe seats are more likely to be Liberal and Liberal seats have larger swings. Disaggregate, and the inverse correlation between majority and swing within each party's seats shows up. We saw in the theoretical section 
that an inverse relation between majority and swing is consistent with a good many different assumptions about voter behavior-the simplest being the likelihood that floating seats have more floating voters.

\section{Conclusions}

We highlight a number of reasons why voters in safe and marginal seats may behave differently. In particular, differences may emerge if voters' decisions are made up of a combination of expressive and instrumental motives, and the instrumental motive is stronger in marginal seats because voters in such constituencies expect to have a better chance of determining the result. We then analyze general election results between 1950 and 2015 in Britain to look for a relationship between a constituency's majority and its likely swing between Labour and Conservative at the next election. We find that the strongest swings in the direction of the national swing are to be found in seats that are neither too safe nor too marginal. Our model would suggest that this might be because very safe seats have fewer floating voters, while marginal seats are dominated by instrumental voting, which might be less responsive to changes in parties' valences than its expressive counterpart. However, seats where the main contest was between Conservative and Liberal Democrat (or formerly Liberal) showed a more straightforward inverse relation between majority and swing.

Investigating the possibility that it is the distance of a seat from the 'bellwether' seat (the one that would be most marginal if the election as a whole were on a knife-edge) did not produce significantly different results from those obtained using majority. However, putting both bellwether and majority into our regression sustains the relationship between swing and the former but not the latter, though the high collinearity between the two means that this final result must be treated with caution.

Acknowledgements We would like to thank the Leverhulme Trust for funding the project of which this article is a part, and for comments and suggestions, the participants in the seminars at Exeter University's economics department and Centre for Elections, Media and Studies; also the reviewers of the first version of this article.Open Access This article is distributed under the terms of the Creative Commons Attribution 4.0 International License (http://creativecommons.org/licenses/by/4.0/), which permits unrestricted use, distribution, and reproduction in any medium, provided you give appropriate credit to the original author(s) and the source, provide a link to the Creative Commons license, and indicate if changes were made.

\section{References}

Blais, A., \& Rheault, L. (2011). Optimists and sceptics: Why do people believe in the value of their single vote? Electoral Studies, 30(1), 77-82.

Buchanan, J. M. (1954). Individual choice in voting and the market. Journal of Political Economy, 62(4), 334-343.

Butler, D., \& Butler, G. (2000). British political facts. Basingstoke: Palgrave Macmillan.

Butler, D., \& Butler, G. (2006). British political facts since 1979. Basingstoke: Palgrave Macmillan.

Clarke, H. D., Sanders, D., Stewart, M. C., \& Whiteley, P. (2004). Political choice in Britain. Oxford: OUP.

Curtice, J., \& Steed, M. (1980). An analysis of the voting. Appendix 2 of D. Butler \& D. Kavanagh, The British general election of 1979. London: Macmillan.

Curtice, J., \& Steed, M. (1988). Analysis. Appendix 2 of D. Butler and D. Kavanagh, The British general election of 1987. London: Macmillan. 
Curtice, J., \& Steed, M. (1992). The results analysed. Appendix 2 of D. Butler and D. Kavanagh, The British general election of 1992. London: St Martin's Press.

Curtice, J., Fisher, J., \& Steed, M. (2005). The results analysed. Appendix 2 of D. Kavanagh \& D.Butler, The British general election of 2005 Basingstoke: Palgrave Macmillan.

Denver, D., Hands, G., \& McAllister, I. (2003). Constituency marginality and turnout in Britain revisited. Journal of Elections, Public Opinion and Parties, 13(1), 174-194.

Jacoby, W. G. (2009). Ideology and vote choice in the 2004 election. Electoral Studies, 28(4), 584-594.

Palmer, H. D., Whitten, G. D., \& Williams, L. K. (2013). Who should be chef? The dynamics of valence evaluations across income groups during economic crises. Electoral Studies, 32(3), 425-431.

Price, S., \& Sanders, D. (1998). By-elections, changing fortunes, uncertainty and the mid-term blues'. Public Choice, 95(1/2), 131-148.

Riker, W., \& Ordeshook, P. C. (1973). An introduction to positive political theory. Englewood Cliffs: Prentice-Hall.

Sanders, D., Clarke, H., Stewart, M. C., \& Whiteley, P. (2011). Downs, Stokes and the dynamics of electoral choice. British Journal of Political Science, 41(2), 287-314.

Steed, M. (1970). An analysis of the results. Appendix 2 of D. Butler and M. Pinto-Ducshinsky, The British general election of 1970. London: Macmillan.

Tullock, G. (1971). The charity of the uncharitable. Western Economic Journal, 9(4), 379-392.

Whiteley, P., \& Seyd, P. (2002). High-intensity participation-the dynamics of party activism in Britain. Ann Arbor: University of Michigan Press.

Whiteley, P., Seyd, P., Richardson, J., \& Bissell, P. (1994). Explaining party membership: The case of the British Conservative party. British Journal of Political Science, 24(1), 79-94. 